\title{
Alfonso Reyes en dos tiempos. Entre el arielismo y la doble experiencia literaria: La venganza creadora y La cena'
}

\author{
Alfonso Reyes in two periods. Between "arielismo" \\ and the double literary experience: La venganza creadora y La cena
}

\author{
PABLO APARICIO DURÁN \\ Universidad de Granada \\ España \\ padnew@yahoo.es
}

Resumen. Es sabido que Alfonso Reyes dejó una enorme impronta intelectual y literaria no sólo en la literatura de su país, Méjico, sino en toda la literatura hispanoamericana. Pero, aparte de las dimensiones de la huella dejada por el autor, lo realmente interesante es el terreno que pisa, $y$ ese, para nosotros, es el terreno ideológico. Así, en el presente artículo ofrecemos una panorámica general sobre la significación cultural del autor mejicano, precisamente para tratar de delimitar que una cosa son las ideologías culturales explícitas y otra cosa es el inconsciente ideológico/literario implícito. En este sentido, se ha efectuado el análisis de dos cuentos del prolífico escritor de Monterrey (La venganza creadora y La cena) en relación con otros dos de Edgar Allan Poe y Ernest Hemingway (Allá en Michigan y La casa Usher, respectivamente).

Palabras clave: Alfonso Reyes; inconsciente ideológico literario; relectura; análisis textual; literatura hispanoamericana.
Abstract. As it is generally known Alfonso Reyes left a huge intellectual and literary imprint not only on the literature of his country, Mexico, but on Latin American literature as a whole. Nonetheless, besides the extent of the author's literary footprint, the true interest, in our opinion, relies on the ideological ground on which it is etched. Therefore, the present article offers a general overview of the cultural importance of the Mexican author, precisely to try to define the fact that explicit cultural ideologies are one thing and the implicit ideological/literary unconscious is another. It is in this sense that we have analyzed two of Reye's short stories (La venganza creadora y La cena) in relation to two others by Edgar Allan Poe and Ernest Hemingway (Up in Michigan and The Fall of the House of Usher, respectively).

Keywords: Alfonso Reyes; literary ideological unconscious; re-reading; textual analysis; Latin American literature.

\footnotetext{
I Para citar este artículo: Aparicio Durán, Pablo (20I3). Alfonso Reyes en dos tiempos. Entre el arielismo y la doble experiencia literaria: La venganza creadora y La cena. Alabe 7 [www.revistaalabe.com]

(Recibido 29-O6-20I2; aceptado o8-OI-2OI3)
} 


\title{
Alfonso Reyes en dos tiempos. Entre el arielismo y la doble experiencia literaria: La venganza creadora y La cena'
}

\author{
Alfonso Reyes in two periods. Between "arielismo" \\ and the double literary experience: La venganza creadora y La cena
}

\author{
PABLO APARICIO DURÁN \\ Universidad de Granada \\ España \\ padnew@yahoo.es
}

Resumen. Es sabido que Alfonso Reyes dejó una enorme impronta intelectual y literaria no sólo en la literatura de su país, Méjico, sino en toda la literatura hispanoamericana. Pero, aparte de las dimensiones de la huella dejada por el autor, lo realmente interesante es el terreno que pisa, $y$ ese, para nosotros, es el terreno ideológico. Así, en el presente artículo ofrecemos una panorámica general sobre la significación cultural del autor mejicano, precisamente para tratar de delimitar que una cosa son las ideologías culturales explícitas y otra cosa es el inconsciente ideológico/literario implícito. En este sentido, se ha efectuado el análisis de dos cuentos del prolífico escritor de Monterrey (La venganza creadora y La cena) en relación con otros dos de Edgar Allan Poe y Ernest Hemingway (Allá en Michigan y La casa Usher, respectivamente).

Palabras clave: Alfonso Reyes; inconsciente ideológico literario; relectura; análisis textual; literatura hispanoamericana.
Abstract. As it is generally known Alfonso Reyes left a huge intellectual and literary imprint not only on the literature of his country, Mexico, but on Latin American literature as a whole. Nonetheless, besides the extent of the author's literary footprint, the true interest, in our opinion, relies on the ideological ground on which it is etched. Therefore, the present article offers a general overview of the cultural importance of the Mexican author, precisely to try to define the fact that explicit cultural ideologies are one thing and the implicit ideological/literary unconscious is another. It is in this sense that we have analyzed two of Reye's short stories (La venganza creadora y La cena) in relation to two others by Edgar Allan Poe and Ernest Hemingway (Up in Michigan and The Fall of the House of Usher, respectively).

Keywords: Alfonso Reyes; literary ideological unconscious; re-reading; textual analysis; Latin American literature.

\footnotetext{
I Para citar este artículo: Aparicio Durán, Pablo (20I3). Alfonso Reyes en dos tiempos. Entre el arielismo y la doble experiencia literaria: La venganza creadora y La cena. Alabe 7 [www.revistaalabe.com]

(Recibido 29-O6-20I2; aceptado o8-OI-2OI3)
} 
I.- La significación cultural de Alfonso Reyes (I889-I952) es clave para entender la literatura hispanoamericana del siglo XX. Es más, creemos que su verdadera importancia reside en el hecho de que el calado y la fecundidad de sus ideas arraiga y se desarrolla en la obra de otros escritores (desde la de un joven Octavio Paz o un Borges hasta la de un Carlos Fuentes) cuya obra creativa es mucho más conocida; es decir, Alfonso Reyes aparece como uno de los «fundadores de la literatura mexicana ${ }^{2}$, en particular, e hispanoamericana, en general, de manera tan solo evidente a los ojos de quienes estudian dicha literatura. Y es que, efectivamente, la persona y la obra de Alfonso Reyes adquieren rápidamente el carácter de autoridad que interesa sobre todo a una elite cultural, entre o alrededor de la cual gravitan los escritores que transforman dichas ideas en el producto ideológico que llamamos literatura (Rodríguez, I990). En ese sentido Alfonso Reyes es un paladín ${ }^{3}$ de esas ideas y actitudes en relación con la cultura, y, dentro de ésta, con la literatura. Así, configurando y articulando sus ideas estéticas, tanto en sus trabajos teóricos como artísticos, Alfonso Reyes se establece, ya a una edad bien temprana, como forjador de una base ideológica y estética para las letras y las ideas de su tiempo en Hispanoamérica hasta nuestros días.

Fenómenos como el realismo mágico, y aun su éxito editorial (el «boom latinoamericano»), deben su desarrollo al autor -filólogo, crítico, poeta, ensayista y narrador- de Monterrey por una serie de razones que podemos enunciar así: I) la asimilación de lo hispano/ibérico y lo europeo por parte de la «inteligencia americana» ${ }^{4} ; 2$ ) y como consecuencia de lo anterior, el llamado «neobarroco» ${ }^{5}$, que surge de - o puede verse como- una doble fusión: por un lado la de la tradición áurea española y la hispanoamericana -y ésta a la altura del final de su segunda fase de constitución, es decir, en la fase posrevolucionaria y, por tanto, ya de independencia, sí, pero de revolución fracasada ${ }^{6}, \mathrm{e}$ ideológicamente a merced de «la reconversión positivista que supone la fenomenología» en sus dos vertientes o discursos: uno «puro y esencialista» y otro «totalmente político y comprometido con la realidad, reforzada esta última posición con el corpus teórico del

\footnotetext{
${ }^{2}$ Vid. Stanton, A. (1998). "Presentación” en A. Reyes y O. Paz. Correspondencia (p. 44). México: Fundación Octavio Paz/Fondo de Cultura Económica.

${ }^{3}$ Empleamos el término en el mismo sentido que Alvar. Cfr. Alvar, M. (I989). Alfonso Reyes y España. Nueva revista de filología hispánica, 37 (2), 299-304.

${ }^{4}$ Vid. Reyes, A. (1992). Notas sobre la inteligencia americana. En Antología del pensamiento político, social y económico de América latina (Alfonso Reyes). Madrid: Ediciones de Cultura Hispánica.

5 Para una interpretación del término distinta a la nuestra, véase Arturo Dávila, S. (2009). El neobarroco sin lágrimas: Góngora, Mallarmé, Alfonso Reyes et al., Hipertexto, 9, 3-35.

${ }^{6}$ Fracasada en tanto que revolución burguesa contra el imperialismo de los EEUU. Pero esta es una cuestión que escapa al propósito de nuestro trabajo. Para una explicación completa de las distintas fases de la literatura hispanoamericana desde el período colonial hasta la Revolución, pasando por la Independencia, véase la imprescindible Introducción al estudio de la literatura hispanoamericana, de J.C. Rodríguez y A. Salvador (2005, Madrid: Akal).
} 
marxismo idealista y fenomenológico» (Rodríguez y Salvador, 2005: 325)-; por otro, la superación de la novela sentimental hispanoamericana mediante la traslación/transculturación de las corrientes literarias europeas al contexto de la América hispana?, es decir, a su propia problemática, a saber: localismo vs. universalismo, América vs. Europa, o lo que es lo mismo, la vieja dicotomía civilización/barbarie, aún vigente bajo nuevas formas igualmente politizadas, etcétera; y 3 ) la visión de la Naturaleza americana como elemento singularizador clave de toda la literatura hispanoamericana ${ }^{8}$, pero que, en el caso del mejicano Alfonso Reyes, será su visión trans-histórica, pero paradigmática, de un lugar, el Valle de México, el cual se compara con la meseta castellana en Visión de Anáhuac, en un ejercicio estilístico/idealista del todo emparentado con la visión azoriniana de Castilla ${ }^{9}$.

2.- La idea de la cultura hispanoamericana ya madura y autónoma, es decir, distinta e independiente de la europea, proviene de la corriente ideológica de la que Alfonso Reyes es deudor: el «arielismo» del uruguayo José Enrique Rodó. En efecto, Rodó parte de una concepción elitista del mestizaje (otro de los problemas clave de la literatura hispanoamericana en general), según la cual, la civilización latinoamericana (aquí sí, latina y no sólo hispana) emparentaría directamente con la «vieja Europa», frente a la civilización norteamericana; en definitiva, frente al imperialismo de dicho país. Es decir: tendríamos, por un lado, al calibán yanqui (idea tomada de Groussac), y, por otro, al ariel intelectual criollo de cultura europea, etc. (Rodríguez y Salvador, 2005: I49-I7I). La lectura que Alfonso Reyes hace de Rodó se resume en dos puntos: a) el aprecio y la vinculación a la cultura greco-latina y b) la «misión solidaria» de los pueblos (frente al imperialismo, se entiende) y su mutua dependencia (Reyes, 1992). Esta y no otra es la idea que late, por ejemplo, en las Notas sobre la inteligencia americana de nuestro avezado helenista (con varias traducciones sobre sus espaldas). Pero, no lo olvidemos, Alfonso Reyes es también un experto y profundo conocedor de la literatura inglesa (y angloamericana), no menos importante en su formación que la greco-romana; no por otra razón se ganó a Borges ya en su primer encuentro ${ }^{\mathrm{IO}}$.

3.- El idioma y la visión del mundo que mediante él se expresa en la obra de Alfonso Reyes son, pues, un producto de una legitimación de la tradición lingüística española (encumbrada en los Siglos de Oro españoles) y el caldo de ideologías de la época (el

\footnotetext{
${ }^{7}$ Con respecto a la influencia de la literatura clásica española en Alfonso Reyes, es evidente que su temprana y larga estancia en España, donde se formó en los estudios filológicos en la compañía de su compatriota Pedro Henríquez Ureña y Américo Castro, entre otros, y bajo el magisterio de don Ramón Menéndez Pidal, iba a ser determinante en su estilo literario, pues su siempre presente mejicanidad se desarrolla en consonancia con una honda conciencia de dicha tradición. Cifr. Alvar (1989).

${ }^{8}$ Para una explicación cabal tanto de este concepto como del de la dicotomía civilización/barbarie en la formación de las literaturas hispanoamericanas, véase la ya citada Introducción al estudio de la literatura hispanoamericana.

${ }^{9}$ Loc. cit. Como observa Manuel Alvar, Alfonso Reyes tiene mucho de azoriniano; es más, llega a sentir «devoción» por Azorín.

${ }^{\text {IO }}$ Lo cuenta el propio Borges al principio de la entrevista que le hizo Osvaldo Ferrari. Vid. Ferrari, O. y Borges, J. L. (r992). Diálogos. Buenos Aires: Seix Barral.
} 
idealismo eminentemente neokantiano, positivista y fenomenológico - de corte krausista y orteguiano, en este caso-, y, como hemos dicho, la dicotomía civilización/barbarie en su nueva expresión, digamos, posmodernista, específica de la cultura hispanoamericana).

Pero la lengua no nos plantea aquí ningún problema: Reyes es deudor de Bello en lo lingüístico/político, en tanto que preconizador de la unidad de la lengua española frente al imperialismo que se extiende por el mundo, y en especial por el continente americano, en lengua inglesa. Es por ello - aparte su amor por España-que las ideas lingüísticas de Alfonso Reyes no adolecen de prejuicios americanicistas, ya que no sólo no opone ningún reparo a la consideración de la metrópoli como «solar de la lengua», sino que mediante su magisterio en el Colegio de México, enseñará historia literaria española muy de acuerdo con los postulados de la «escuela de Menéndez Pidal», su maestro durante sus años de estancia en España. Quizá sea esta una de las razones por las que el Alfonso Reyes poeta es uno de los menos vanguardistas de la Vanguardia poética hispanoamericana.

Así pues, Alfonso Reyes huye del localismo recalcitrante. Pero no es sólo el tipo de lengua, sino su espíritu o genio lo que, desde una concepción, eso sí, idealista de lo lingüístico/literario americano, se pone en entredicho: ¿tienen el español de América y su literatura un espíritu o genio propio? Esta es una preocupación general de todas las plumas hispanoamericanas desde Bello. Sólo que la de Alfonso Reyes será una reivindicación meramente cultural y no idiomática; una defensa de lo español en o desde lo americano, que expresará en los términos idealistas de la tan traída y llevada relación alma/cuerpo:

El alma, el patrimonio espiritual, se conserva en el vehículo de la lengua. El cuerpo, el patrimonio físico, sólo se resguarda y se organiza mediante una operación de símbolo, en la lengua también (...) La determinante es la cultura y su expresión es la lengua. Cuando recibimos como lengua nacional la española, con ella recibimos el acervo espiritual de España -y del mundo en general filtrado por España- para aquí mezclarlo con algunas modalidades autóctonas, aquéllas y sólo aquéllas que podían ser viables. Nuestra lengua es el excipiente que disuelve, conserva y perpetúa nuestro sentido nacional. (Reyes, I99I: 26I-262)

Puro Hegel. 
I. - Pero la «significación cultural» de la que hablábamos al principio es también -y sobre todo- significación ideológica. Sólo que la ideología de la que hemos hablado hasta ahora, la política (incluyendo la lingüística), no siempre se corresponde exactamente con la que se desprende del estilo literario usado, ya que éste, además de seguir determinadas mentalidades o visiones del mundo, sigue también modas y, en todo caso, ideologías aún más inconscientes que las que de forma más explícita salen a relucir en el discurso de la moral, la política o la religión. Y afirmamos que la ideología del Alfonso Reyes literato es, en gran medida, aún la del final del siglo XIX europeo: por un lado, la corriente realista, y, por otro, la ideología de la doble experiencia lockiana, es decir, un romanticismo rezagado de carácter angloamericano. A saber: la doble experiencia «significa que no sólo las experiencias sensoriales provocan la formación de ideas, sino que las ideas se experiencian entre sí» (Rodríguez, 20I2: 63).

2.- Veámoslo con la lectura de dos cuentos de Reyes: La venganza creadora y $L a$ cena, ambos de estilos bien distintos: uno, realista/naturalista; el otro, de un romanticismo a la hechura del gothic tale, propio de la ideología de la doble experiencia psicologicista:

a) La venganza creadora nos puede recordar -y, es claro, no hablamos aquí de influencias- al Hemingway (realista y romántico a la vez) de Up in Michigan; sobre todo, por el tipo de conflicto amoroso que representan ambos relatos: el de la tensión sexual entre un hombre y una mujer en un ambiente doméstico tradicional en el que la mujer (Almendrita, en el cuento de Reyes, y Liz en el de Hemingway) es víctima, por su naturaleza, del instinto del hombre. Almendrita, sin embargo, acaba dominando la situación que en un principio la domina; esto es: acaba resolviendo la situación, su conflicto interior en relación con los hombres de su entrono, por medio de esa misma naturaleza, llevándola hasta sus últimas consecuencias: casi transfigurándose en un sentido carnal, venciendo al hombre en el terreno de la sexualidad, es decir, manejando su instinto en un alarde de feminidad, pura expresión física que no sólo le sale por los «poros», sino que «lanza» contra los hombres como la «metralla». Liz, en cambio, cae víctima de Jim, como antes lo había hecho el ciervo por él abatido en la jornada de caza, tras la cual, come y bebe Whisky (tal vez lo único que lo diferencia de un cazador primitivo) y poco menos que viola a la joven enamorada. Pero, el simbolismo de Hemingway (la tela que cubre al ciervo y la chaqueta con que se cubre Liz tras el encuentro en el «duro y astillado» entablado del almacén, de la que ella se desprenderá para taparlo a él, pasando así a su frío interior y exterior, en la frialdad de la neblina del bosque, etc.) es ya otro, digamos, más funcional, por patético, y es por ello muestra de que Hemingway sigue - como muchos hoy- siendo, en el fondo, un romántico. 
La venganza creadora de Alfonso Reyes es, por el contrario, aún un cuento realista: Almendrita nos recuerda más bien a las Bovary, Karenina u Ozores, sólo que sin ninguna de sus respectivas contradicciones, sin el remordimiento, y, por eso mismo, quizá haya que recordar un carácter como el de Pepita Jiménez. En la rápida evolución del personaje de Almendrita, ella se muestra resolutiva, directa, más sana; en definitiva, triunfante - al contrario que Liz- sobre los hombres, que, sin quedar derrotados por sus «armas de mujer», sí sufren una especie de turbación, propia de la «competición entre machos» por la hembra, sobre todo cuando ninguno de ellos es claramente el dominante. En efecto, ya no se trata del ser angelical al modo de la María de Jorge Isaacs, con Almendrita nos las habemos con una mujer que es, piensa y desea (Rodríguez, 20Io). Así, nos encontramos ante un cuento de tradición realista, y aun naturalista, amén de algunos toques de erotismo (bastante explícito, por otra parte) que también hay en el relato de Hemingway.

b) La cena, en cambio, recuerda y mucho a Poe ${ }^{\mathrm{I}}$; en concreto, a La casa Usher. Efectivamente, casi podemos ir párrafo por párrafo estableciendo paralelismos: la descripción de un ambiente que determina el estado de ánimo (ya de por sí hipersensible en unos o en otros personajes), la sensación de fatalismo entre acontecimientos inesperados, la perplejidad y la agudeza de observación ante los extraños personajes. Pero aquí vamos a fijarnos nada más que en cuatro de los aspectos que apuntalan mejor nuestro aserto, precisamente por ser las coincidencias que más claramente ilustran la reelaboración que Reyes hace del cuento del autor estadounidense y de la serie de elementos típicos (y tópicos) que lo componen al modo de la literatura de la doble experiencia:

I) En el cuento de Poe, la llegada del protagonista a la mansión de los Usher se produce «through a singulary drary tract of country» ("por unas tierras singularmente lóbregas'). Para el protagonista de La Cena, en cambio, un paraje o un camino «lóbrego» es ya algo demasiado asendereado. No. El personaje/narrador nos habla aquí de que tuvo que «correr a través de calles desconocidas». Pero, con una salvedad: que, para el lector moderno, el de Reyes, lo inquietante no es lo desconocido sino el mismo desconocimiento en medio de lo cotidiano, de ahí la explotación de lo «imprevisto» pero lógico (en dicha lógica de la doble experiencia (Rodríguez, 20I2: 68-69) y el gusto por la formación/deformación del sueño. Al contrario que en el cuento de Poe, donde todo es premonición, en el de Reyes, todo es incógnita, aunque haya luego una conclusión o, mejor, un cierre en forma de huída que luego veremos.

\footnotetext{
${ }^{\text {II }}$ No parece haberse dado cuenta la crítica de esta evidente relación (que -aquí sí- nos atrevemos a llamar influencia o fuente del cuento) y, menos aún, de la ideología de la doble experiencia que subyace a este tipo de literatura, vigente aún en el cuento de Alfonso Reyes. Las interpretaciones al uso de este relato hablan tan sólo de lo «onírico", del «presurrealismo», de «la flor de Coleridge», de la relación con el padre muerto, etc. Cfr. Madrigal Rodríguez, M. E. (2007). "Espejismos y una sombra: La cena de Alfonso Reyes", Literatura Mexicana, I8 (2), I79-I93 y Willis Rob, J. (I98I). “La cena de Alfonso Reyes, cuento onírico: ¿surrealismo o realismo mágico?”, Thesaurus: Boletín del instituto Caro y Cuervo, 36 (2), 272-283.
} 
2) La invitación/aceptación motivada. El protagonista de La casa Usher acepta la invitación de su viejo amigo Roderick por la singularidad/autenticidad de la petición (por carta); la misma que la invitación (la esquela) le transmite al protagonista de La cena ${ }^{\text {I2. }}$.

«Yo siempre consiento en las experiencias de lo imprevisto. El caso, además, ofrecía singular atractivo: el tono, familiar y respetuoso a la vez, con que el anónimo designaba a aquellas señoras desconocidas; la ponderación: «iAh, si no faltara!...», tan vaga y tan sentimental, que parecía suspendida sobre un abismo de confesiones, todo contribuyó a decidirme.»

3) El recurso a la pintura: dos pintores, el Fuseli de Poe y el Echave el Viejo de Reyes desempeñan un papel clave al ilustrar esa doble experiencia: la referencia a sus cuadros potencia, predispone para, la percepción ideal del aspecto físico de los personajes inquietantes, de humanidad puesta en duda, alienada, etcétera. Sólo que en el cuento de Poe el pintor en cuestión es el personaje de Roderick Usher, cuyos cuadros reflejan fielmente lo indefinible, lo abrumador, la ensoñación, etc.; Fuseli es sólo el referente real al que Poe remite al lector para que se haga una idea de la pintura de su personaje, cuyo valor reside precisamente en su ideal indefinición. Y en este sentido Fuseli no logra lo que Roderick consigue con creces: para el narrador del cuento de Poe, el primero es «demasiado concreto» en la plasmación de dichas ensoñaciones; el segundo, en cambio, consigue sobrecoger verdaderamente con sus «abstracciones». Alfonso Reyes, por su parte, recurre a un pintor mejicano del siglo XVII para cumplir la misma función: porque no menos indefinible y abstracta es la imagen que Reyes quiere transmitir apoyándose en la pintura de Baltasar Echave de Orio, pues aún está por ver qué cosa sea exactamente esa «expresión de piedad [de las misteriosas anfitrionas del protagonista de La cena «grabada hasta en la dureza de los rasgos» y esas caras iluminadas como «astros enormes y fantásticos». Lo que sí está claro es su sentido: como venimos diciendo, lo significativo de ambos relatos es el desdoblamiento de una de las categorías propias de la ideología de la doble experiencia: ciencia experimental vs. ciencia de lo no asible (Rodríguez, 2OI2: 7I).

4) La huída: tanto al final de La casa Usher como de La cena, asistimos a una saturación de dicha experiencia duplicada o sensibilidad exacerbada y a la consiguiente huida/despertar de sus protagonistas.

\footnotetext{
${ }^{\text {I2 }}$ Para la importancia en la ideología burguesa de las cenas, las sobremesas, los espejos, etc., véase Tras la muerte del aura (En contra y a favor de la Ilustración), op. cit., pp. 80,86 y 87.
} 


\section{Conclusión}

Hemos visto cómo, partiendo de las ideas de sus predecesores en la formación de la literatura/conciencia hispanoamericana, así como de su formación intelectual (tan emparentada con España), Alfonso Reyes desarrolla un discurso de síntesis y universalización de lo hispanoamericano/mejicano a través de su particular desarrollo del llamado «arielismo».

Con todo, la afirmación cultural e ideológica que esto conlleva no es óbice para que, en el caso de nuestro autor, las corrientes literarias europeas con las que voluntariamente se hermana dicho movimiento se dejen informar, también, por las formas y la ideología de otra tradición literaria, la angloamericana, perteneciente al fenómeno que históricamente lo amenaza política y culturalmente: el imperialismo estadounidense. Esto no quiere decir más que lo que ya hemos afirmado: que la producción ideológicoliteraria demuestra lo que el discurso político, moral, religioso, científico, etc., dice y no dice. Es decir: una cosa son las ideologías culturales explícitas y otra es el inconsciente ideológico/literario implícito (Rodríguez, 2002). 


\section{Bibliografía}

- Alvar, M. (I989). Alfonso Reyes y España, Nueva revista de filología hispánica, 37 (2), 299-304.

- Arturo Dávila, S. (2009). El neobarroco sin lágrimas: Góngora, Mallarmé, Alfonso Reyes et al., Hipertexto, 9, 3-35

- Ferrari, O. y Borges, J. L. (1992). Diálogos. Buenos Aires: Seix Barral.

- Hemingway, E. (2004). Up in Michigan, en The First Forty-Nine Stories. London: Arrow Books.

- Madrigal Rodríguez, M. E. (2007). Espejismos y una sombra: La cena de Alfonso Reyes. Literatura Mexicana, I8 (2), I79-193.

- Poe, E. A. (1998). Selected Tales. New York: Oxford University Press.

- Reyes, A. (1993). Obras completas. México: Fondo de Cultura Económica.

- - (т99I). Discurso por la lengua. En E. Ortega (ed.). Redacción y composición, vol. II (pp. 26I-262). La Habana: Pueblo y Educación.

- - (1992). Antología del pensamiento político, social y económico de América latina (Alfonso Reyes). Madrid: Ediciones de Cultura Hispánica.

- - (1998). Correspondencia: Alfonso Reyes / Octavio Paz. México: Fundación Octavio Paz / Fondo de Cultura Económica.

- Rodríguez, J. C. (I990). Teoría e historia de la producción ideológica. Madrid: Akal

- - (20I2). Tras la muerte del aura. En contra y a favor de la Ilustración. Granada: Universidad de Granada.

- - (2002). De quéhablamos cuando hablamos de literatura. Granada: Comares.

- - y Salvador, Álvaro (2005). Introducción al estudio de la literatura hispanoamericana, $3^{\text {a }}$ edición. Madrid: Akal.

- - (20I0), Un ejercicio de lectura (De cómo Azorín se inventa a la mujer al leer el Quijote), Alabe, 1, [www.revistaalabe.com]

- Willis Rob, J. (I98I): "La cena” de Alfonso Reyes, cuento onírico: ¿surrealismo o realismo mágico?, en Thesaurus: Boletín del instituto Caro y Cuervo, Tomo 36, $N^{\circ} 2$, pp. 272-283. 


\title{
Enseñar literatura en entornos digitales ${ }^{1}$
}

\author{
Teaching Literature in a Digital Environment
}

\author{
JOSÉ MARÍA GARCÍA LINARES
}

IES Güímar España

kaluitas@yahoo.es

\begin{abstract}
Resumen. Una sociedad se caracteriza sobre todo por constituir un sistema de elementos interconectados. Cualquier mutación que tenga lugar en las parcelas del conocimiento en las que se subdivide el cuerpo social influye, inevitablemente, sobre el resto de las disciplinas. En un contexto como éste, las TIC han puesto de manifiesto la necesidad de formar a los ciudadanos en la utilización de nuevas herramientas que son hoy imprescindibles para la interacción del individuo con el contexto social. En consecuencia, las instituciones educativas deben hacer frente a las nuevas necesidades generadas por los cambios socioculturales y económicos mediante la aplicación o introducción de dichas tecnologías en los nuevos planes de estudio.
\end{abstract}

Palabras clave: literatura; tecnologías; TIC; hipertexto; educación.
Abstract. A society is characterized mostly by being a system of interconnected elements. Any mutation that takes place in any of the fields of knowledge in which the social body is subdivided influences, inevitably, the rest of disciplines. In such a context, new technologies have made evident the need to educate citizens in the use of new tools that are nowadays essential for the interaction between the human being and the social context. As a consequence, educative institutions must cope with the new need brought about by the socio-cultural and economic changes. This can be done through the application or introduction of such technologies in the new syllabus.

Key words: Literature; Technologies; NICT; Hipertext; Education.

\footnotetext{
${ }^{1}$ Para citar este artículo: García Linares, José María (2013). Enseñar literatura en entornos digitales. Álabe 7. 


\section{Introducción}

Desde hace veinte años, con los primeros acercamientos teóricos - científicos al objeto hipertexto, la bibliografía al respecto no ha dejado de aumentar. Monografías que anunciaban virtudes extraordinarias, colecciones de artículos en los que se advertía de sus peligros y fosas, congresos y jornadas en donde se debatieron formas clásicas de lectura frente a las hipertextuales... Y siempre con la vista puesta en teorías postestructuralistas que todavía hoy van de la mano de cualquier discusión e interpretación que se produzca sobre lo hipertextual, con el condicionante que ello supone a la hora de elaborar una teoría real y contemporánea.

Afortunadamente el tiempo ha puesto cada afirmación en su sitio y hoy la cuestión del hipertexto ${ }^{2}$ parece mucho más concretada y más orientada hacia el campo en el que se desenvuelve como pez en el agua, como pez en el aula, diríamos. El hipertexto ha pasado de ser el sustituto mesiánico del libro al complemento ideal y fabuloso en los entornos académicos.

\section{Anclados en el océano}

Rueda Ortiz (2007: 15-31) contextualiza el debate y el desarrollo de las nuevas tecnologías y la educación en la postmodernidad. Para llegar a esta "condición postmoderna", así denominada por Lyotard (1989), la modernidad valoró la idea de progreso por encima de cualquier otra como señal de avance del hombre hacia la libertad y el conocimiento. Se pasaba así de la superstición a la razón. Junto con esta idea de progreso, el saber humano iría librando al hombre y el dominio de ese saber o razón sería la realización de toda la especie. Sin embargo, las dos guerras mundiales pusieron de manifiesto que todo el programa y todas las esperanzas que se habían puesto sobre el dominio de ese conocimiento habían fracasado. Es así como Nietzsche desarrolla el discurso que nace tras la modernidad y que será seguido por pensadores como Heidegger, Foucault, Derrida y Deleuze. Se cuestiona, en consecuencia, el humanismo grecocristiano y el cogito cartesiano, con lo que el "yo" comienza a tambalearse hasta quedar reducido a una verdad metafísico-gramatical.

La afirmación nietzscheana, tan manipulada durante el siglo XX, de que Dios ha muerto no es más que la metáfora de la muerte de la Razón Ilustrada con sus pretensiones de Absoluto. Con esta muerte de Dios también muere el hombre, es decir, muere

\footnotetext{
${ }^{2}$ Para el concepto de hipertexto, sus características y precedentes, véanse Aarseth, E. (2004), Borrás Castanyer, L. (Ed.) (2005), Cassany, D. (2012), Goicoechea, M. (2007), Landow, G. (2008), Mendoza, A. (2010a, 2010b, 2012a, 2012b) Moreno Hernández, C. (1998), Moulthrop, S. (2003), Orozco Vera, M. J. (2005), Pajares Tosca, S. (2004), Romera Castillo, J. (1996), Ruiz Domínguez, M. ${ }^{a}$ M. (2012), Tabernero, R. (2012), Tortosa, V. (2008) y Romero López, D. y Sanz Cabrerizo, A. (Eds.) (2008).
} 
el humanismo. Desaparece el concepto moderno de hombre y deja de existir un sujeto en el que proyectarse, siendo el presente la única dimensión vigente. Es, por tanto, la postmodernidad una nueva concepción del tiempo y del la historia en donde no existe el progreso.

El pensamiento reunido bajo el rótulo de postmodernidad abandona la creencia en los grandes relatos junto con sus deseos de unidad. Dichas narraciones siempre fueron intentos de comprenderlo todo. Eran sistemas que tenían una pretensión de totalidad y como tal, actuaban de manera totalitaria, esto es, excluyendo a través de distintos mecanismos otras posibilidades. El hecho de que hoy esas grandes narraciones hayan perdido credibilidad tiene como consecuencia el derrumbe de las viejas verdades que conlleva otra crisis profunda de orientación. Una crisis que afecta a todas las instituciones sociales, entre ellas la escuela.

"La escuela ha estado centrada en un modelo pedagógico y comunicativo excesivamente libresco", en palabras de Ruiz Ortiz (2007: 29), apoyado en lo memorístico y al margen de las transformaciones culturales contemporáneas donde la emergencia de las nuevas tecnologías de la información ocupan un lugar central. Colom y Mèlich (1995: 60-61) señalan que un sistema educativo debería tener las siguientes cualidades: interactividad, conectabilidad, movilidad y capacidad de adaptación, omnipresencia o democratización y mundialización o educación sin fronteras ni diferencias. Por su parte, Pérez Tornero (2000: 33) entiende que el nuevo entorno digital que se está creando introducirá cambios en la situación cultural y educativa que hoy conocemos. Las transformaciones que propone serían las siguientes: De la centralización a la dispersión reticular de la difusión y control de la información y la educación; de la rigidez en programas mediáticos y en currículos educativos a la flexibilidad y operatividad; de modelos difusionistas en medios e instruccionistas en educación a modelos interactivos y construccionistas; de la estandarización de productos e itinerarios educativos a su diversificación y personalización; de la regulación nacional de los media y de la educación a la internacionalización y globalización; de la pasividad del espectador y del estudiante a la búsqueda de interacción y participación.

En una sociedad como la actual, en red, se requiere de un enfoque radicalmente distinto, pues, al tradicional cara a cara entre profesor y alumnado a través de saberes petrificados de antemano.

Es importante señalar, como hace Rueda Ortiz (2007: 30) que "no se trata de una enseñanza sustentada exclusivamente en los medios y nuevas tecnologías, se trata más bien de una enseñanza que transita por diferentes medios y lenguajes, ajustándose cada vez más a las necesidades cognitivas, expresivas, afectivas y sociales de los estudiantes". 


\section{Nuevos navegantes}

Ruiz Tarragó (2007: 142) sostiene la tesis de que las escuelas de los siglos XIX y XX fueron concebidas alrededor del profesor como guardián exclusivo del conocimiento del alumnado, y así era él quien controlaba el acceso al currículo y su evaluación. Cita a Bentley (2000) para quien las escuelas están concebidas para transmitir el conocimiento en una sola dirección; se encargan de distribuir la información, es decir, racionan y controlan el flujo informativo; están integradas verticalmente, organizadas en departamentos y materias; son jerárquicas y tienen un marcado carácter de vigilancia y, por último, señala Bentley que operan con rutinas normalizadas y recurren a métodos normalizados de medición del rendimiento.

En una sociedad del conocimiento como la de hoy parece necesario que la preparación del alumnado para prosperar en un entorno cada vez más abierto sea distinta. Ruiz Tarragó (2007: 142) señala cualidades como "la creatividad, la adaptabilidad, y la predisposición a la innovación" como esenciales para la persona educada que trabaja con símbolos, datos y relaciones. La necesidad de proponer nuevos modelos de enseñanzaaprendizaje se hace imperiosa en una sociedad que se ha ido adaptando, en líneas generales, a los nuevos tiempos pero en la que la institución educativa sigue funcionando como lo hacía hace cincuenta años. El mundo de entonces y el de ahora son muy diferentes, como apunta Ruiz Tarragó (2007: 37-39). El entorno que conformó la niñez y la adolescencia de buena parte de quienes hoy ocupan posiciones de liderazgo en la sociedad era un mundo con un consumo muy limitado, que no tenía televisión en color, ni telebasura, ni manga, ni material pornográfico en los quioscos, ni música rap, ni móviles, ni ordenadores, ni videojuegos, ni sitios en Red. Tampoco había los enormes problemas de consumo de drogas que hay actualmente. La familia también era diferente, más amplia en líneas generales, con las madres a menudo en casa y los abuelos próximos a los pequeños. Ejercía un importante control sobre niños y adolescentes. La familia valoraba mucho la escuela y veía al profesorado como fuente de disciplina y autoridad, como conductor de un proceso de adquisición de conocimiento y de formación del carácter. Ir al colegio era el camino para algunos que debían seguir y para otros un estímulo o alternativa a una opción laboral prematura.

El entorno social de antes era muy diferente, por tanto. El aparato político-religioso de la época de la dictadura imponía a la juventud elementos de control social como la práctica religiosa obligatoria, el servicio militar obligatorio y el servicio social obligatorio.

Los horizontes de la infancia y de la adolescencia eran muy limitados. Para muchos la lectura era la principal puerta abierta a la imaginación, cosa que no ocurre en nuestro tiempo, aunque los libros también forman parte del contexto del joven. 
En contraste, el mundo de hoy en día, tanto el real como el virtual, está lleno de incentivos y de actividades interesantes al margen de la escuela y también en contraposición a ella (Feixa, 2008: 31-50). Es mucho más urbano, está completamente motorizado, lleno de movimiento. Los chicos y las chicas conocen a mucha más gente, tienen comunicación permanente con grupos de amistades e incluso tratar con desconocidos por la red se ha convertido en algo habitual. Es decir, todo el entorno de los jóvenes ha cambiado salvo la institución escolar que lo acoge obligatoriamente.

El alumno contemporáneo tiene una autodeterminación psicológica que antes no tenía. Ahora es un individuo que quiere cosas, que las exige y que frecuentemente las consigue o bien reacciona, a veces de modo desproporcionado. Es un individuo que consume continuamente productos y asimila estereotipos culturales, convertido en el objetivo de una intensa e incesante presión publicitaria que se extiende a la familia y a todos los menores de edad como colectivo, y este consumo alimenta industrias legales e ilegales que crecen y obtienen enormes beneficios.

Los modelos de conducta que observa transmiten a menudo incivismo e indiferencia por las cosas sociales, así como superficialidad y grosería. Conductas llenas de violencia, de egoísmo y de búsqueda de satisfacciones inmediatas llenan las pantallas de los teléfonos móviles, de las videoconsolas, de los ordenadores y del cine o la televisión.

Las tecnologías digitales son muy familiares para esta juventud (Gabelas Barroso y Marta Lazo, 2011: 3-16). Les proporcionan niveles de interacción, de autonomía, de diversión y también desasosiego difíciles de imaginar para sus mayores. Muchos disponen de ordenador, móvil, DVD, TV en su habitación, consola de videojuegos, cámara digital, reproductor de MP3, grabador de CD, Internet... Por tanto, la influencia del entorno tecnológico es enorme, hasta tal punto que los correos electrónicos, los sitios Red o los SMS son parte integral de la vida del joven del siglo XXI. El resultado de este entorno ubicuo y del enorme volumen de interacciones es que los estudiantes piensan y procesan la información de una manera diferente a la de generaciones anteriores.

Así las cosas, parece que no tiene mucho sentido esperar que las pautas de comportamiento del alumnado sean parecidas a las de épocas pasadas, impregnadas de autoritarismo y limitaciones de todo tipo. Tampoco se le puede exigir al profesorado que día tras día intente imponer esa disciplina férrea y que lo haga para enseñar pautas éticas y para evitar el desorden y, a veces, la violencia, como manifiesta Gómez (2009) en todo su estudio. No queremos decir con esto que no sea imprescindible en los centros educativos trabajar en y para la convivencia. Lo que parece que falta hoy es una redefinición profunda del papel del alumnado y del profesorado. Es necesaria una nueva oferta educativa, un nuevo diseño del aprendizaje y de la actividad del alumnado e innovaciones importantes en la concepción y la tarea del profesorado y de su alumnado, como puede observarse en Cebrián de la Serna (2011:23-31). 


\section{Reestructuración y cambios}

Desplegar este panorama social y cultural de esta nueva generación nos parecía fundamental para conectar con lo que se está haciendo en la enseñanza universitaria, sobre todo a distancia, desde el punto de vista de lo hipertextual. A este respecto, Apollon (2004: 345-366) estudia, a propósito de la educación superior y la visión del aprendizaje electrónico, los cambios evolutivos que el uso de las TIC ha sufrido hasta llegar a nuestros días e indaga en los significados de expresiones cada vez más usuales como "sociedad del conocimiento", "economía de la información", "aprendizaje a lo largo de la vida". La primera de las fases (1956-1985) que señala es la instrumental, asociada a la máquina. El aprendizaje se concibe en este momento como un sistema de producción, en el que las tecnologías son vistas como aceleradores de aprendizajes. El paradigma dominante de esta enseñanza es el conductismo. Es el momento, también, del auge y decepción posterior del papel de la inteligencia artificial, debido a que esta primera fase careció de un marco conjunto que pudiera combinar visiones asociadas al software y al hardware con una poderosa ideología de comunicación que sostuviera esas esperanzas primeras. Era necesario que surgiera primero un escenario prácticamente nuevo.

La segunda de las fases estudiadas por Apollon (de 1985 en adelante) está relacionada con la desaparición del modernismo industrial ortodoxo y su sustitución por una sociedad postindustrial tardía, de la que habla también Lyon (2005: 101-106). El paradigma dominante es el de la emergencia de una sociedad de la información, es decir, el paradigma de la comunicación por encima de todo lo demás. Surge, pues, un nuevo marco de referencia en el que operan sociedad, economía, educación, cultura y subjetividad. En el proceso de globalización, la comunicación y sus contenidos actúan como el logos central. Estar en línea implica pertenecer a una comunidad universal, hasta tal punto que dicha conectividad se ha convertido en un habitus social distintivo.

Una de las claves que va a determina el cambio de rumbo en la educación de las soeiedades modernas es para Apollon (2004: 354-362) es la del final del pensamiento sectorial. Tras la Segunda Guerra Mundial la sociedad quedó compartimentada en esferas autónomas de actividad, de conocimientos. Los intercambios físicos e ideológicos y el traspase de una esfera a otra eran vistos como no naturales. El primer modelo sectorial ofrecía tres estadios: El sector primario (agricultura y recursos naturales), el sector secundario (producción y procesamiento industrial) y el terciario (servicios, administración, educación).

Dicho esquema comienza a tambalearse a partir de los años 60 como consecuencia del crecimiento de la infraestructura del consumo de masas. La metáfora sectorial se ve sustituida por otras nuevas, tales como la del trabajo en red o la autosatisfacción individual. 
En las universidades el control del conocimiento canónico es sustituido progresivamente por redes de colaboración auto-organizadas. Se subordinan todos los marcos sectoriales anteriores a instancias particulares del paradigma general de trabajo en red globalizado, como consecuencia de ese crecimiento del que hablábamos antes, es decir, la educación empieza a transformarse también en una mercancía que se consume, en un área de aplicación del paradigma de la sociedad de la información y en una esfera de la autorrealización de los alumnos.

Por tanto, los sistemas de conocimiento tradicionales y los de comunicación de dicho conocimiento sufren profundos cambios. El primero, como es lógico, es que el control tradicional de los saberes (especificación, estandarización y validación) es desafiado y ampliado a la vez. Hay que señalar, igualmente, que el impacto de la individualización reflexiva ha forzado a los "dueños" de ese conocimiento a compartir el poder con el alumno a través de deliberaciones, jornadas, mesas redondas, debates, etc. En tercer lugar, la importancia del criticismo humanista de la ciencia y de las disciplinas académicas ha sido subestimada. Los estudiantes evalúan críticamente la durabilidad y la complejidad del conocimiento y de las habilidades proporcionadas por sistemas docentes. Por último, y no menos importante, el estudiante individual posee un contrapoder en cuanto a su acceso a los recursos de investigación proporcionados por Internet y sus herramientas.

La reestructuración, por tanto, parece evidente. Los cambios apuntan no sólo a la redefinición del sistema educativo existente sino también al desarrollo total del potencial docente fuera del mismo. Los hombres y mujeres de la sociedad de la información y del conocimiento son agentes de su propia educación, lo cual, independientemente de la posibilidad de desarrollo personal que la población tiene al alcance, puede esconder otro tipo de intereses que Feenberg (2002) comenta en uno de sus artículos. La cuestión, para le autor, no se limita sólo a la educación, sino que afectaría al modelo mismo de sociedad que refleja en cualquier institución la lógica de la producción moderna, obsesionada por la eficacia conseguida por la mecanización y la gestión. Para demasiados administradores, las grandes cuestiones no son educacionales. Las implicaciones financieras de la nueva enseñanza digital o electrónica son lo que realmente les importa. Esperan usar la nueva tecnología para superar la crisis en los gastos de la educación superior, sobre todo a distancia. Si es cierto que, por un lado, las nuevas tecnologías pueden mejorar la calidad de la enseñanza, por otro supone reducir costes en la impartición de las clases y obtener amplios beneficios con el aumento de las matrículas en ese esquema de educación y aprendizaje a lo largo de la vida. Los cursos, cierto es, pueden empaquetarse y venderse generando continuos ingresos.

De esta visión generalista sobre el papel de las nuevas tecnologías en la educación queremos pasar a un análisis más particular centrado en el papel del hipertexto en la enseñanza y en las redefiniciones de las figuras del profesor y el alumno. 


\section{Hipertexto y enseñanza}

Por sus características propias, según Dotras (1997: 333), "el hipertexto tiene un gran potencial pedagógico pudiendo llegar incluso a constituirse en el recurso material académico por excelencia". La práctica docente actual, si bien no lo considera el recurso por antonomasia, sí le ha otorgado a dicha herramienta un valor de apoyo y profundización. Las ventajas, como afirma Dotras (1997: 333) son múltiples: "El ahorro de tiempo, resultado del rápido acceso a la información y de la selección del contenido en función de los intereses de cada lector. Esto permite una lectura individualizada que posibilita omitir la información irrelevante y que, por consiguiente, libera el aprendizaje de lecturas redundantes. [...] [Sin embargo] la falta de eficacia que el uso de los hipertextos ha puesto de manifiesto en la práctica real se debe, principalmente, a que la excesiva libertad lectora que permite se ha revelado contraproducente en determinadas situaciones de aprendizaje. Los problemas ante los que puede encontrarse un estudiante son los siguientes: la sensación de lectura fragmentada e inacabada, la dificultad para visualizar la construcción formal del material, la dificultad para localizar un determinado bloque de contenido, [...] la navegación sin rumbo o la inadecuación entre la finalidad del estudiante y la estructura o tipo de actividad que le ofrece el hipertexto".

La reflexión de Dotras es certera a la hora de apuntar posibles inconvenientes del uso hipertextual en el ámbito educativo puesto que las posibles soluciones que ella ofrece para no errar en su uso se han ido aplicando posteriormente, esto es, la necesidad de integrar en los hipertextos - base mecanismos de ayuda como son las rutas definidas de lectura o los mapas gráficos conceptuales. Se fomenta así la autonomía del aprendizaje y dicho aprendizaje, autoaprendizaje, puede ser más dinámico y controlado.

No consiste su uso en la mera asimilación de contenidos sino que favorece la capacidad de asociación de ideas, la reflexión crítica y el pensamiento conceptual. Canadell (2005: 213-225) considera la didáctica de la literatura en el entorno digital como relación de varios elementos: el profesor-facilitador, el estudiante-educando y el medio virtual. Es evidente que tanto el profesor como el alumno se ponen en contacto en un nuevo entorno y para ello es necesario que el estudiante tenga predisposición, esto es, educabilidad, y el educador capacidad de influencia o educatividad.

Brioschi y Di Grirolamo (1998: 66-67) afirman que "la enseñanza de la literatura ya no se asimila a la enseñanza de la historia de la literatura. [...] Hoy en día, el encuentro con los textos adquiere un papel decisivo. Es determinante la experiencia vivida por el estudiante en clase". Es decir, se enseña a leer de manera distinta en cada época, como afirman Núñez Ruíz y Campos Fernández-Fígares (2005). 
Para que la experiencia directa con los textos esté garantizada y para que los beneficios de ese acercamiento sean cuantitativos para el alumno, el profesor debe ser un instructor o facilitador de conocimientos que orienta de manera individualizada el proceso de aprendizaje de cada alumno de un aula. Este nuevo profesor, que puede ser presencial o a distancia, según sea el contexto en el que realice su labor, bien la Universidad (a distancia), bien la Educación Secundaria (presencia física), requiere más tiempo de preparación, presta más atención a las motivaciones del estudiante y domina los recursos tecnológicos directamente vinculados a su materia.

Feenberg (2002) advierte sobre la amenaza de automatización que sobrevuela la figura del profesor cualificado. Las estrategias de automatización son muy antiguas. Los trabajadores cualificados son caros y sería una solución para reducir gastos. La historia de esta reducción podría comenzar a principios del XIX cuando los fabricantes textiles del norte de Inglaterra descubrieron que podían reemplazar el trabajo cualificado por el no cualificado usando la maquinaria. Sólo la mención de este proceso ya resulta inquietante.

La idea de reemplazar a profesores por ordenadores también viene de lejos, si bien es un sector minoritario el que la defiende. Sin embargo, ha conseguido hacerse oír en el debate educativo actual, en muchas ocasiones con el disfraz de expresiones corrientes y cada vez más usuales como la de la instrucción individualizada al propio ritmo.

La educación tecnológica, termina Feenberg, debe ser estructurada en un contexto más amplio porque, primeramente, no es una cuestión tecnológica. Refleja las relaciones cambiantes entre la administración y el profesionalismo, lo cual implica también cuestiones como modelos de profesión, calidad y control. Hay que defender un sistema en el que el ordenador y la figura del profesor estén conjugados porque la interacción entre docente y discente debe continuar siendo el eje de la educación.

En cuanto al educando, en palabras de Canadell (2005: 219) los estudios sociológicos y pedagógicos demuestran que su cultura, sobre todo si es joven, “cada vez es más visual y se estructura más en forma de red que linealmente, es decir, que se pone mucho más en juego la capacidad de relacionar ideas y conceptos que la de acumular datos". Advierte, además, de que la interacción del alumno con el profesor ha disminuido, si tenemos en cuenta los hábitos individualistas de la sociedad actual. Por tanto, puede hablarse también de alumnado presencial o a distancia, este último, generalmente, universitario, puesto que en la Educación Secundaria la presencia física es obligatoria.

En cualquier caso, la relación entre el alumno y el estudiante de literatura en entornos digitales se desarrolla en ese tercer elemento que Canadell llama medio virtual y que se materializa en el hipertexto a través de diversas páginas web, portales temáticos, bases de datos, blogs educativos, etc. 
Los cambios o redefiniciones de los que acabamos de hablar formarían parte del proceso de deconstrucción de la escuela que Rueda Ortiz (2007: 302-314) expone en su obra. El conocimiento científico, tecnológico o artístico, dice la autora, está enmarcado ahora en un nuevo medio, entendido no como la representación de algo, sino como un modo de actuar en el mundo, en la cultura. Sería una nueva epistemología en la que el que observa participa en dicha observación, es decir, una nueva pedagogía de la conectividad en donde son fundamentales la importación y exportación de campos del saber.

La puesta en marcha de esquemas como éstos no consiste sólo en llevar la escuela tal cual, con su concepción, espacios, modelos, etc., al entorno virtual. Ese traslado, justamente, es el que necesita, según Rueda Ortiz (2007: 304) "una deconstrucción de la escuela tradicional". Sin ella, los desaciertos y las malas interpretaciones afectarán a la adaptación de la escuela a los cambios de la sociedad. Una pedagogía de la hipertextualidad, en palabras de nuestra autora:

Tendría que asumir el reto de la fragmentación de la (en) línea, que para nosotros considera varios aspectos relacionados:

- La fragmentación de la idea de secuencia fija de etapas lógicas del pensamiento, y la apertura a la posibilidad de las inteligencias múltiples.

- La fragmentación de la subjetividad, desplegada en diversos escenarios de actuación, de expresión y de experiencia, por lo tanto asumir la diferencia (en tanto différance) en la formación de la identidad.

- La fragmentación del currículum y de los contenidos de aprendizaje y la creación de redesinterrelacionadas (colectivas y conectivas) de temas de conocimiento.

- La fragmentación de los binomios: maestro-alumno; emisor-receptor; escritor-lector; para genera multiplicidad de vías, mediaciones y mediadores de aprendizaje, e inventar una nueva escritura difuminada en una red activa tanto de autores, lectores, escritores, como de medios o lenguajes de expresión en una complejidad ecológica del fenómeno comunicativo y educativo.

- La fragmentación de modelo educativo homogéneo y homogeneizador y la apertura a nuevos itinerarios de formación y a todos los públicos.

En definitiva, de lo que alerta Rueda Ortiz es de uno de los problemas que existen hoy en día en la Educación Secundaria, en donde esa nueva educación se ha visto reducida a la instalación paupérrima de algunos cañones de luz y pizarras electrónicas junto con la adquisición de un número de ordenadores inferior al de alumnos por aula. Ha habido muy pocas de las transformaciones de las que habla en su estudio Ruiz Tarragó (2007: 235-265), esto es, no se ha transformado ni flexibilizado el currículo como debiera, ni los roles del profesor y el alumno, ni la organización de la plantilla de los centros ni, mucho menos, la arquitectura de los mismos. Grau (2008) señala en su artículo que más del $80 \%$ del alumnado de ESO en España reconoce no haber usado nunca o casi nunca el ordenador en clase. Las opciones están limitadas al aula de informática, a la que no se puede acceder asiduamente. 
Estamos, pues, en un estadio intermedio entre la educación tradicional y la electrónica, como se deja entrever en el estudio de Rodríguez Prada (2012).

Nos gustaría concluir con una de las aproximaciones más certeras y realistas a la aplicación del hipertexto en la enseñanza de la literatura. Pajares Tosca (2004: 121-153) dedica un capítulo de su estudio precisamente a las posibilidades prácticas que puede albergar un hipertexto educativo (en un entorno universitario) a partir de varios proyectos cuyo tema central es el Retrato de un artista adolescente, de Joyce.

Las características en las que ella y su equipo de trabajo se basan para la creación de estos materiales son, por ejemplo, la toma de decisiones y de actuación que deben llevar a cabo los estudiantes para avanzar en la lectura, la importancia a la hora de elegir un enlace u otro o las distintas interpretaciones que una estructura multilineal ofrece a quien experimenta con ella.

Sus conclusiones al respecto, una vez finalizado el curso en el que fue aplicado el proyecto, son sumamente interesantes. Entre ellas, es un sistema el del hipertexto educativo muy recomendable siempre que se lleven a cabo en grupos pequeños, pues la masificación de las aulas impide que se pueda realizar la labor docente si no es con una clase magistral.

Al tener los estudiantes que expresar sus ideas en distintos foros se fuerzan a reflexionar más sobre el significado de lo que lo hacen en un seminario cuando intervienen oralmente. A la vez, la estructura hipertextual favorece la comparación y discusión de ideas y a concentrarlas en pocas palabras y a encontrar un lugar adecuado para enlazarlas, de manera que la actividad sirve para desarrollar la reflexión y la síntesis.

La distancia entre los acercamientos teóricos a la nueva educación o posteducación y la práctica docente diaria son, como se demuestra a lo largo de todo el estudio de Pajares Tosca, todavía enormes. Para la autora, el hipertexto educativo puede servir para complementar la educación tradicional al insistir en el desarrollo de nuevas formas de pensar alentadas por el uso de las nuevas tecnologías, nunca para sustituirlo. 


\section{Conclusiones}

Parece evidente que la sociedad en la que vivimos está indisolublemente unida a la tecnología, cuyo núcleo lo constituye la digitalización de la información. Las llamadas Tecnologías de la Información y de la Comunicación (TIC) han puesto de manifiesto la relevancia en esta era posmoderna de la información y la necesidad de que los ciudadanos conozcan y dominen dichas herramientas tecnológicas.

En este contexto, la educación, como eslabón imprescindible del sistema social, debe abordar e incorporar de manera satisfactoria estos nuevos medios de conocimiento puesto que son imprescindibles para que los individuos puedan interaccionar con la realidad que les circunda en todos sus niveles.

Así, la diferencia entre esta sociedad posmoderna y formaciones sociales anteriores estriba en la mutabilidad de los procesos y los hechos, en la velocidad, en los sistemas en red y en el flujo de información. Mientras ámbitos como la ciencia o la economía han evolucionado a un ritmo vertiginoso, la educación no ha sabido hacer frente a las demandas generadas por la presente situación social, en el sentido de que los cambios que se esperaban, la adaptación del sistema a una nueva realidad, no se han materializado debidamente. La velocidad con la que la reflexión teórica propone y sugiere esas modificaciones hace imposible que la práctica docente diaria pueda incorporarse con garantías al nuevo reto educativo. La flexibilidad necesaria en espacios, tiempos y currículos, tan necesaria para los nuevos modelos de enseñanza-aprendizaje, sigue sin llegar, al menos en la Enseñanza Secundaria Obligatoria. Tan solo alguna referencia a la competencia digital, difícilmente evaluable cuando la mayoría de los centros españoles de Secundaria no disponen de un ordenador por alumno. Para adecuarse a las nuevas necesidades, el sistema educativo debería garantizar la interactividad, la conectabilidad, la movilidad, la capacidad de adaptación a los contextos reales, la omnipresencia y la mundialización, con el objetivo de que el ciudadano pudiera ser agente de su propia educación. Sin embargo, todo hace indicar que nos encontramos en un nivel intermedio entre los sistemas educativos tradicionales y los sistemas educativos electrónicos y posmodernos, de ahí, posiblemente, las numerosas contradicciones entre la teoría y la práctica docente. 


\section{Bibliografía}

- Aarseth, E. (2004). "La literatura ergódica". En Literatura y Cibercultura, Domingo Sánchez Mesa (Ed.), págs.118-145. Madrid: Arco/Libros.

- Aguirre Romero, J. M. ${ }^{a}$ (2011). "La transformación de la sociedad lectora con el impacto tecnológico: el futuro lector". En Literatura e Internet. Nuevos Textos. Nuevos Lectores, Salvador Montesa, págs. 19-40. Málaga: AEDILE.

- Apollon, D. (2004). La educación superior y la visión del e-aprendizaje. En Literatura y Cibercultura, Domingo Sánchez Mesa (Ed.), (pp. 345-366). Madrid: Arco/Libros.

- Barroso Villar, M. E. (2005). La comunicación literaria en el nuevo universo tecno- lógico. En Comunicación, universo artístico y nuevas tecnologías, María Elena Barroso Villar (Ed.), (pp. 57-93). Sevilla: Alfar.

- Borrás Castanyer, L. (Ed.) (2005). Textualidades electrónicas. Nuevos escenarios para la literatura. Barcelona: Editorial UOC.

- _ (2008). "Lit[art]ure. La literatura en tiempos de Internet". En Quimera. Revista de literatura, n 290, págs. 26-31. Barcelona: Ediciones de Intervención Cultural S. L.

- _ (2009). "Literatura de nueva generación". En Quimera. Revista de literatura, N. ${ }^{\circ}$ 305, págs. 46-50. Barcelona: Ediciones de Intervención Cultural S. L.

- __ (2011). "Nuevos lectores, nuevos modos de lectura en la era digital". En Literatura e Internet. Nuevos textos. Nuevos lectores, Salvador Montesa, págs. 41-66. Málaga: AEDILE.

- __ (2012). “Territorio hipertextual: lectura y enseñanza 2.0”. En Antonio Mendoza (coord.), Leer hipertextos. Del marco hipertextual a la formación del lector literario, págs. 33-52. Barcelona: Octaedro.

- Brioschi, F. y Di Girolamo, C. (1998). Introducción al estudio de la literatura. Barcelona: Ariel.

- Canadell, R. (2005). La docencia de la literatura catalana desde la perspectiva del elearning. En Textualidades electrónicas. Nuevos escenarios para la literatura, Laura Borrás Castanyer (Ed.), (pp. 213-225). Barcelona: Editorial UOC.

- Cañas, D. y González Tardón, C. (2010). ¿Puede un computador escribir un poe- ma de amor? Tecnorromanticismo y poesía electrónica. Madrid: Devenir. 
- Castells, M. (1997). La era de la información. Economía, sociedad y cultura. I. La sociedad red. Madrid: Alianza.

- Cassany, D. (2006). Tras las líneas. Sobre la lectura contemporánea. Barcelona: Anagrama.

- ___ (2012a). "La metamorfosis digital: cambios, ventajas y riesgos de leer y escribir en la red”. En Las TIC en la escuela, nuevas herramientas para viejos y nuevos problemas, Daniel Goldin, Marina Kriscautzky y Flora Perelman, págs. 217-236. Barcelona: Océano.

- ___ (2012b). En_linea. Leer y escribir en la red. Barcelona: Anagrama.

- Cebrián de la Serna, M. (2011). "Los centros educativos en la sociedad de la infor- mación y el conocimiento". En Procesos educativos con TIC en la sociedad del conocimiento, M. Cebrián y Mª J. Gallego Arrufat, Ma . J. (Coord.) (2011).Madrid: Pirámide.

- Cleger, O. (2012). "Pantallas saturadas / cuerpos opacos: la ficción hipertextual en lengua española". En Leer hipertextos. Del marco hipertextual a la formación del lector literario, Antonio Mendoza (coord.), págs. 53-72. Barcelona: Octaedro.

- Colom, A. y Mèlich, J. C. (1995). Después de la modernidad. Barcelona: Paidós.

- Dotras, A.M. (1997). Hipertexto: lectura y aprendizaje. En Literatura y Multimedia, José Romera Castillo et alii (Eds.), (pp. 333-335). Madrid: Visor Libros.

-Feenberg, A. (2002). La enseñanza "Online" y las Opciones de la Modernidad. Hermeneia. Obtenido el 12 de febrero de 2012 desde http://www.hermeneia.net/sala_de lectura/a_feenberg_ensenanza_on_line.htm

- Feixa, C. (2008). “La generación digital”. En Videojuegos y aprendizaje, Begoña Gros (Coord.), págs. 31-50. Barcelona: Grao.

- Gabelas Barroso, J. A. y Marta Lazo, C. (2011). "Adolescentes en la cultura digital”. En Jóvenes interactivos, Estrella Martínez Rodrigo y Carmen Marta Lazo, págs. 3-16. La Coruña: Netbiblo.

- García Carcedo, P. (Cood.) (2008). Enseñanza virtual y presencial de las literatu- res. Madrid: Grupo Editorial Universitario.

- Gil, M. y Rodríguez, J. (2011). El paradigma digital y sostenible del libro. Madrid: Trama. 
- GOICOECHEA, M. a (2007). "Hyper-Paradigm". En Literatures in the Digital Age: Theory and Praxis, Amelia Sanz and Dolores Romero (eds.), págs. 18-21. Newcastle: Cambridge Scholars Publishing.

- GÓMEZ GÓMEZ, A. (2009). La escuela sin ley. Madrid: La Esfera de los Libros.

- GRAU,A.(2008). Pizarra contizas en la era de Internet. Diario El País. Obtenido el 12 de enero de 2012 desde http://elpais.com/diario/2008/04/08/sociedad/1207605601_850215. html

- Koskimaa, R. (2007). "El reto del cibertexto: enseñar literatura en el mundo digital”. En http://www.uoc.edu/in3/hermeneia/esp/espais/sala_K.html.

- Landow, G. (2008). Hipertexto 3.0. Teoría crítica y nuevos medios en la era de la globalización, Barcelona: Paidós.

- Lanier, J. (2011). Contra el rebaño digital. Un manifiesto. Barcelona: Debate.

- Leibrandt, I. (2008). Las herramientas electrónicas en la didáctica de la Literatura. Pamplona: EUNSA.

- Lucía, J. M. (2012). Elogio del texto digital. Madrid: Fórcola.

- Lyotard, J.F. (1989). La condición postmoderna. Madrid: Cátedra.

- Martínez, M. (2008). "Modelos mixtos de enseñanza-aprendizaje presencial y virtual”. En Enseñanza virtual y presencial de las literaturas, Pilar García Carcedo (coord.), págs. 4768. Madrid: Universidad Complutense.

- Martos Núñez, E. (1998). “Leer en red”. En Puertas a la lectura, N. o 5, págs. 15-19. Universidad de Extremadura.

- __ (2004). "Lectura y nuevas tecnologías". En Puertas a la lectura, N. 17, págs. 147155. Universidad de Extremadura.

- _ (2006). "Tunear los libros: Fanfiction, blogs y otras prácticas emergentes de lectura”. En Ocnos: revista de estudios sobre lectura, N. ${ }^{\circ}$ 2, págs. 63-78. Universidad de CastillaLa Mancha.

- __ (2010). "De la República de las Letras a Internet: de la ciudad letrada a la cibercultura y las tecnololgías del siglo XXI". En Álabe: Revista de Investigación sobre Lectura y Escritura, N. ${ }^{\circ}$ 1: http://nevada.ual.es:81/alabe/index.php/alabe/article/view/10 
- Mendoza, A. (2010a). "La lectura del hipertexto literario. El despliegue de referentes, conexiones e hipervínculos en la formación del lector". En El lector ante la obra hipertextual, A. Mendoza y C. Romea (Coords.), págs. 143-174. Barcelona: Horsori.

- ___ (2010b). “Canon e hipertexto”. En El invisible anillo, 12, págs. 32-45.

- __ (2012a). "Presentación”. En Leer hipertextos. Del marco hipertextual a la formación del lector literario, Antonio Mendoza (coord.), págs. 9-32. Barcelona: Octaedro.

- ___ (2012b). "Leer hipertextos de papel: sobre el lector y sus hipervínculos cognitivos". En Leer hipertextos. Del marco hipertextual a la formación del lector literario, Antonio Mendoza (coord.), págs. 73-100. Barcelona: Octaedro.

- Montesa, S. (ed.) (2011). Literatura e Internet. Nuevos textos. Nuevos lectores. Málaga: AEDILE.

- Moreno Hernández, C. (1998). Literatura e Hipertexto. De la cultura manuscrita a la cultura electrónica. Madrid: UNED.

- Moulthrop, S. (2003). “El hipertexto y la política de la interpretación”. En María José Vega (Ed.), Literatura hipertextual y teoría literaria, págs. 23-31. Madrid: Marenostrum.

- Núñez Ruiz, G. y Campos Fernández-Fígares, M. C. (2005). Cómo nos enseñan a leer. Estudio preliminar de Juan Carlos Rodríguez. Madrid: Akal.

- Orozco Vera, M. J. (2005). "Literatura e hipertexto: hacia una lectura creativa". En María Elena Barroso Villar (Ed.), Comunicación, universo artístico y nuevas tecnologías, págs. 95-112. Sevilla: Alfar.

- Pardo Salgado, C. (2008). Las TIC: Una reflexión filosófica. Barcelona: Laertes Educación.

- PajaresTosca, S. (2004). Literatura Digital. El paradigma hipertextual. Cáceres: Universidad de Extremadura.

- Perez Tornero, J.M. (2000). Comunicación y educación en la sociedad de la información. Nuevos lenguajes y conciencia crítica. Barcelona: Paidós.

- Rodríguez De Las Heras, A. (2011). "Nuevos espacios para la escritura digital". En Literatura e Internet. Nuevos textos. Nuevos lectores, Salvador Montesa, págs. 101-108. Málaga: AEDILE. 
-Rodríguez Prada, J. R. (2012). Conflicto y reforma en la educación (1986-2010). Los años decisivos: de la rebelión estudiantil a las consecuencias de la LOGSE. Madrid: Trafican- tes de sueños.

- Romera Castillo, J. (1996). "Literatura y nuevas tecnologías". En José Romera Cas- tillo et alii (Eds.), Literatura y multimedia, págs. 13-82. Madrid: Visor Libros.

- Romero López, D. y Sanz Cabrerizo, A. (Eds.) (2008). Literaturas del texto al hipermedia, Barcelona: Anthropos.

- Rueda Ortiz, R. (2007). Para una pedagogía del hipertexto. Una teoría de la deconstrucción y la complejidad. Barcelona: Anthropos.

- Ruiz Domínguez, M. a M. (2012). "Hipertextos, metaficción y fantasía, en Corazón de Tinta”. En En Leer hipertextos, Antonio Mendoza (Coord.), págs. 149-134164. Barcelona: Octaedro.

- Ruiz Tarragó, F. (2007). La nueva educación. Madrid: Fundación Everis.

- Tabernero, R. (2012). "La hipertextualidad como fundamento de construcción en la literatura "iluminada": La formación del lector en el libro-álbum y en el libro ilustrado". En Leer hipertextos, Antonio Mendoza (Coord.), págs. 121-134. Barcelona: Octaedro.

- Tortosa, V. (2008). Una nueva lógica escritural: El hipertexto. En Escrituras digitales. Tecnologías de la creación en la era virtual, Virgilio Tortosa (Ed.), (pp. 51-97). Alicante: Universidad.

- Vilariño Picos, M. ${ }^{\text {a }}$ T. (2011). "Espacio...Ciberespacio...y...Literatura...”. Litera-tura e Internet. Nuevos textos. Nuevos lectores, En Salvador Montesa, págs. 131-146. Málaga: AEDILE. 
I.- La significación cultural de Alfonso Reyes (I889-I952) es clave para entender la literatura hispanoamericana del siglo XX. Es más, creemos que su verdadera importancia reside en el hecho de que el calado y la fecundidad de sus ideas arraiga y se desarrolla en la obra de otros escritores (desde la de un joven Octavio Paz o un Borges hasta la de un Carlos Fuentes) cuya obra creativa es mucho más conocida; es decir, Alfonso Reyes aparece como uno de los «fundadores de la literatura mexicana ${ }^{2}$, en particular, e hispanoamericana, en general, de manera tan solo evidente a los ojos de quienes estudian dicha literatura. Y es que, efectivamente, la persona y la obra de Alfonso Reyes adquieren rápidamente el carácter de autoridad que interesa sobre todo a una elite cultural, entre o alrededor de la cual gravitan los escritores que transforman dichas ideas en el producto ideológico que llamamos literatura (Rodríguez, I990). En ese sentido Alfonso Reyes es un paladín ${ }^{3}$ de esas ideas y actitudes en relación con la cultura, y, dentro de ésta, con la literatura. Así, configurando y articulando sus ideas estéticas, tanto en sus trabajos teóricos como artísticos, Alfonso Reyes se establece, ya a una edad bien temprana, como forjador de una base ideológica y estética para las letras y las ideas de su tiempo en Hispanoamérica hasta nuestros días.

Fenómenos como el realismo mágico, y aun su éxito editorial (el «boom latinoamericano»), deben su desarrollo al autor -filólogo, crítico, poeta, ensayista y narrador- de Monterrey por una serie de razones que podemos enunciar así: I) la asimilación de lo hispano/ibérico y lo europeo por parte de la «inteligencia americana» ${ }^{4} ; 2$ ) y como consecuencia de lo anterior, el llamado «neobarroco» ${ }^{5}$, que surge de - o puede verse como- una doble fusión: por un lado la de la tradición áurea española y la hispanoamericana -y ésta a la altura del final de su segunda fase de constitución, es decir, en la fase posrevolucionaria y, por tanto, ya de independencia, sí, pero de revolución fracasada ${ }^{6}, \mathrm{e}$ ideológicamente a merced de «la reconversión positivista que supone la fenomenología» en sus dos vertientes o discursos: uno «puro y esencialista» y otro «totalmente político y comprometido con la realidad, reforzada esta última posición con el corpus teórico del

\footnotetext{
${ }^{2}$ Vid. Stanton, A. (1998). "Presentación” en A. Reyes y O. Paz. Correspondencia (p. 44). México: Fundación Octavio Paz/ Fondo de Cultura Económica.

${ }^{3}$ Empleamos el término en el mismo sentido que Alvar. Cfr. Alvar, M. (I989). Alfonso Reyes y España. Nueva revista de filología hispánica, 37 (2), 299-304.

${ }^{4}$ Vid. Reyes, A. (1992). Notas sobre la inteligencia americana. En Antología del pensamiento político, social y económico de América latina (Alfonso Reyes). Madrid: Ediciones de Cultura Hispánica.

5 Para una interpretación del término distinta a la nuestra, véase Arturo Dávila, S. (2009). El neobarroco sin lágrimas: Góngora, Mallarmé, Alfonso Reyes et al., Hipertexto, 9, 3-35.

${ }^{6}$ Fracasada en tanto que revolución burguesa contra el imperialismo de los EEUU. Pero esta es una cuestión que escapa al propósito de nuestro trabajo. Para una explicación completa de las distintas fases de la literatura hispanoamericana desde el período colonial hasta la Revolución, pasando por la Independencia, véase la imprescindible Introducción al estudio de la literatura hispanoamericana, de J.C. Rodríguez y A. Salvador (2005, Madrid: Akal).
} 
marxismo idealista y fenomenológico» (Rodríguez y Salvador, 2005: 325)-; por otro, la superación de la novela sentimental hispanoamericana mediante la traslación/transculturación de las corrientes literarias europeas al contexto de la América hispana?, es decir, a su propia problemática, a saber: localismo vs. universalismo, América vs. Europa, o lo que es lo mismo, la vieja dicotomía civilización/barbarie, aún vigente bajo nuevas formas igualmente politizadas, etcétera; y 3 ) la visión de la Naturaleza americana como elemento singularizador clave de toda la literatura hispanoamericana ${ }^{8}$, pero que, en el caso del mejicano Alfonso Reyes, será su visión trans-histórica, pero paradigmática, de un lugar, el Valle de México, el cual se compara con la meseta castellana en Visión de Anáhuac, en un ejercicio estilístico/idealista del todo emparentado con la visión azoriniana de Castilla ${ }^{9}$.

2.- La idea de la cultura hispanoamericana ya madura y autónoma, es decir, distinta e independiente de la europea, proviene de la corriente ideológica de la que Alfonso Reyes es deudor: el «arielismo» del uruguayo José Enrique Rodó. En efecto, Rodó parte de una concepción elitista del mestizaje (otro de los problemas clave de la literatura hispanoamericana en general), según la cual, la civilización latinoamericana (aquí sí, latina y no sólo hispana) emparentaría directamente con la «vieja Europa», frente a la civilización norteamericana; en definitiva, frente al imperialismo de dicho país. Es decir: tendríamos, por un lado, al calibán yanqui (idea tomada de Groussac), y, por otro, al ariel intelectual criollo de cultura europea, etc. (Rodríguez y Salvador, 2005: I49-I7I). La lectura que Alfonso Reyes hace de Rodó se resume en dos puntos: a) el aprecio y la vinculación a la cultura greco-latina y b) la «misión solidaria» de los pueblos (frente al imperialismo, se entiende) y su mutua dependencia (Reyes, 1992). Esta y no otra es la idea que late, por ejemplo, en las Notas sobre la inteligencia americana de nuestro avezado helenista (con varias traducciones sobre sus espaldas). Pero, no lo olvidemos, Alfonso Reyes es también un experto y profundo conocedor de la literatura inglesa (y angloamericana), no menos importante en su formación que la greco-romana; no por otra razón se ganó a Borges ya en su primer encuentro ${ }^{\mathrm{IO}}$.

3.- El idioma y la visión del mundo que mediante él se expresa en la obra de Alfonso Reyes son, pues, un producto de una legitimación de la tradición lingüística española (encumbrada en los Siglos de Oro españoles) y el caldo de ideologías de la época (el

\footnotetext{
${ }^{7}$ Con respecto a la influencia de la literatura clásica española en Alfonso Reyes, es evidente que su temprana y larga estancia en España, donde se formó en los estudios filológicos en la compañía de su compatriota Pedro Henríquez Ureña y Américo Castro, entre otros, y bajo el magisterio de don Ramón Menéndez Pidal, iba a ser determinante en su estilo literario, pues su siempre presente mejicanidad se desarrolla en consonancia con una honda conciencia de dicha tradición. Cifr. Alvar (1989).

${ }^{8}$ Para una explicación cabal tanto de este concepto como del de la dicotomía civilización/barbarie en la formación de las literaturas hispanoamericanas, véase la ya citada Introducción al estudio de la literatura hispanoamericana.

${ }^{9}$ Loc. cit. Como observa Manuel Alvar, Alfonso Reyes tiene mucho de azoriniano; es más, llega a sentir «devoción» por Azorín.

${ }^{\text {IO }}$ Lo cuenta el propio Borges al principio de la entrevista que le hizo Osvaldo Ferrari. Vid. Ferrari, O. y Borges, J. L. (r992). Diálogos. Buenos Aires: Seix Barral.
} 
idealismo eminentemente neokantiano, positivista y fenomenológico - de corte krausista y orteguiano, en este caso-, y, como hemos dicho, la dicotomía civilización/barbarie en su nueva expresión, digamos, posmodernista, específica de la cultura hispanoamericana).

Pero la lengua no nos plantea aquí ningún problema: Reyes es deudor de Bello en lo lingüístico/político, en tanto que preconizador de la unidad de la lengua española frente al imperialismo que se extiende por el mundo, y en especial por el continente americano, en lengua inglesa. Es por ello - aparte su amor por España-que las ideas lingüísticas de Alfonso Reyes no adolecen de prejuicios americanicistas, ya que no sólo no opone ningún reparo a la consideración de la metrópoli como «solar de la lengua», sino que mediante su magisterio en el Colegio de México, enseñará historia literaria española muy de acuerdo con los postulados de la «escuela de Menéndez Pidal», su maestro durante sus años de estancia en España. Quizá sea esta una de las razones por las que el Alfonso Reyes poeta es uno de los menos vanguardistas de la Vanguardia poética hispanoamericana.

Así pues, Alfonso Reyes huye del localismo recalcitrante. Pero no es sólo el tipo de lengua, sino su espíritu o genio lo que, desde una concepción, eso sí, idealista de lo lingüístico/literario americano, se pone en entredicho: ¿tienen el español de América y su literatura un espíritu o genio propio? Esta es una preocupación general de todas las plumas hispanoamericanas desde Bello. Sólo que la de Alfonso Reyes será una reivindicación meramente cultural y no idiomática; una defensa de lo español en o desde lo americano, que expresará en los términos idealistas de la tan traída y llevada relación alma/cuerpo:

El alma, el patrimonio espiritual, se conserva en el vehículo de la lengua. El cuerpo, el patrimonio físico, sólo se resguarda y se organiza mediante una operación de símbolo, en la lengua también (...) La determinante es la cultura y su expresión es la lengua. Cuando recibimos como lengua nacional la española, con ella recibimos el acervo espiritual de España -y del mundo en general filtrado por España- para aquí mezclarlo con algunas modalidades autóctonas, aquéllas y sólo aquéllas que podían ser viables. Nuestra lengua es el excipiente que disuelve, conserva y perpetúa nuestro sentido nacional. (Reyes, I99I: 26I-262)

Puro Hegel. 
I. - Pero la «significación cultural» de la que hablábamos al principio es también -y sobre todo- significación ideológica. Sólo que la ideología de la que hemos hablado hasta ahora, la política (incluyendo la lingüística), no siempre se corresponde exactamente con la que se desprende del estilo literario usado, ya que éste, además de seguir determinadas mentalidades o visiones del mundo, sigue también modas y, en todo caso, ideologías aún más inconscientes que las que de forma más explícita salen a relucir en el discurso de la moral, la política o la religión. Y afirmamos que la ideología del Alfonso Reyes literato es, en gran medida, aún la del final del siglo XIX europeo: por un lado, la corriente realista, y, por otro, la ideología de la doble experiencia lockiana, es decir, un romanticismo rezagado de carácter angloamericano. A saber: la doble experiencia «significa que no sólo las experiencias sensoriales provocan la formación de ideas, sino que las ideas se experiencian entre sí» (Rodríguez, 20I2: 63).

2.- Veámoslo con la lectura de dos cuentos de Reyes: La venganza creadora y $L a$ cena, ambos de estilos bien distintos: uno, realista/naturalista; el otro, de un romanticismo a la hechura del gothic tale, propio de la ideología de la doble experiencia psicologicista:

a) La venganza creadora nos puede recordar -y, es claro, no hablamos aquí de influencias- al Hemingway (realista y romántico a la vez) de Up in Michigan; sobre todo, por el tipo de conflicto amoroso que representan ambos relatos: el de la tensión sexual entre un hombre y una mujer en un ambiente doméstico tradicional en el que la mujer (Almendrita, en el cuento de Reyes, y Liz en el de Hemingway) es víctima, por su naturaleza, del instinto del hombre. Almendrita, sin embargo, acaba dominando la situación que en un principio la domina; esto es: acaba resolviendo la situación, su conflicto interior en relación con los hombres de su entrono, por medio de esa misma naturaleza, llevándola hasta sus últimas consecuencias: casi transfigurándose en un sentido carnal, venciendo al hombre en el terreno de la sexualidad, es decir, manejando su instinto en un alarde de feminidad, pura expresión física que no sólo le sale por los «poros», sino que «lanza» contra los hombres como la «metralla». Liz, en cambio, cae víctima de Jim, como antes lo había hecho el ciervo por él abatido en la jornada de caza, tras la cual, come y bebe Whisky (tal vez lo único que lo diferencia de un cazador primitivo) y poco menos que viola a la joven enamorada. Pero, el simbolismo de Hemingway (la tela que cubre al ciervo y la chaqueta con que se cubre Liz tras el encuentro en el «duro y astillado» entablado del almacén, de la que ella se desprenderá para taparlo a él, pasando así a su frío interior y exterior, en la frialdad de la neblina del bosque, etc.) es ya otro, digamos, más funcional, por patético, y es por ello muestra de que Hemingway sigue -como muchos hoy-siendo, en el fondo, un romántico. 
La venganza creadora de Alfonso Reyes es, por el contrario, aún un cuento realista: Almendrita nos recuerda más bien a las Bovary, Karenina u Ozores, sólo que sin ninguna de sus respectivas contradicciones, sin el remordimiento, y, por eso mismo, quizá haya que recordar un carácter como el de Pepita Jiménez. En la rápida evolución del personaje de Almendrita, ella se muestra resolutiva, directa, más sana; en definitiva, triunfante - al contrario que Liz- sobre los hombres, que, sin quedar derrotados por sus «armas de mujer», sí sufren una especie de turbación, propia de la «competición entre machos» por la hembra, sobre todo cuando ninguno de ellos es claramente el dominante. En efecto, ya no se trata del ser angelical al modo de la María de Jorge Isaacs, con Almendrita nos las habemos con una mujer que es, piensa y desea (Rodríguez, 20Io). Así, nos encontramos ante un cuento de tradición realista, y aun naturalista, amén de algunos toques de erotismo (bastante explícito, por otra parte) que también hay en el relato de Hemingway.

b) La cena, en cambio, recuerda y mucho a Poe" ${ }^{\mathrm{I}}$; en concreto, a La casa Usher. Efectivamente, casi podemos ir párrafo por párrafo estableciendo paralelismos: la descripción de un ambiente que determina el estado de ánimo (ya de por sí hipersensible en unos o en otros personajes), la sensación de fatalismo entre acontecimientos inesperados, la perplejidad y la agudeza de observación ante los extraños personajes. Pero aquí vamos a fijarnos nada más que en cuatro de los aspectos que apuntalan mejor nuestro aserto, precisamente por ser las coincidencias que más claramente ilustran la reelaboración que Reyes hace del cuento del autor estadounidense y de la serie de elementos típicos (y tópicos) que lo componen al modo de la literatura de la doble experiencia:

I) En el cuento de Poe, la llegada del protagonista a la mansión de los Usher se produce «through a singulary drary tract of country» ("por unas tierras singularmente lóbregas'). Para el protagonista de La Cena, en cambio, un paraje o un camino «lóbrego» es ya algo demasiado asendereado. No. El personaje/narrador nos habla aquí de que tuvo que «correr a través de calles desconocidas». Pero, con una salvedad: que, para el lector moderno, el de Reyes, lo inquietante no es lo desconocido sino el mismo desconocimiento en medio de lo cotidiano, de ahí la explotación de lo «imprevisto» pero lógico (en dicha lógica de la doble experiencia (Rodríguez, 20I2: 68-69) y el gusto por la formación/deformación del sueño. Al contrario que en el cuento de Poe, donde todo es premonición, en el de Reyes, todo es incógnita, aunque haya luego una conclusión o, mejor, un cierre en forma de huída que luego veremos.

\footnotetext{
${ }^{\text {II }}$ No parece haberse dado cuenta la crítica de esta evidente relación (que -aquí sí- nos atrevemos a llamar influencia o fuente del cuento) y, menos aún, de la ideología de la doble experiencia que subyace a este tipo de literatura, vigente aún en el cuento de Alfonso Reyes. Las interpretaciones al uso de este relato hablan tan sólo de lo «onírico", del «presurrealismo», de «la flor de Coleridge», de la relación con el padre muerto, etc. Cfr. Madrigal Rodríguez, M. E. (2007). "Espejismos y una sombra: La cena de Alfonso Reyes", Literatura Mexicana, I8 (2), I79-I93 y Willis Rob, J. (I98I). "La cena de Alfonso Reyes, cuento onírico: ¿surrealismo o realismo mágico?”, Thesaurus: Boletín del instituto Caro y Cuervo, 36 (2), 272-283.
} 
2) La invitación/aceptación motivada. El protagonista de La casa Usher acepta la invitación de su viejo amigo Roderick por la singularidad/autenticidad de la petición (por carta); la misma que la invitación (la esquela) le transmite al protagonista de La cena ${ }^{\text {I2. }}$.

«Yo siempre consiento en las experiencias de lo imprevisto. El caso, además, ofrecía singular atractivo: el tono, familiar y respetuoso a la vez, con que el anónimo designaba a aquellas señoras desconocidas; la ponderación: «iAh, si no faltara!...», tan vaga y tan sentimental, que parecía suspendida sobre un abismo de confesiones, todo contribuyó a decidirme.»

3) El recurso a la pintura: dos pintores, el Fuseli de Poe y el Echave el Viejo de Reyes desempeñan un papel clave al ilustrar esa doble experiencia: la referencia a sus cuadros potencia, predispone para, la percepción ideal del aspecto físico de los personajes inquietantes, de humanidad puesta en duda, alienada, etcétera. Sólo que en el cuento de Poe el pintor en cuestión es el personaje de Roderick Usher, cuyos cuadros reflejan fielmente lo indefinible, lo abrumador, la ensoñación, etc.; Fuseli es sólo el referente real al que Poe remite al lector para que se haga una idea de la pintura de su personaje, cuyo valor reside precisamente en su ideal indefinición. Y en este sentido Fuseli no logra lo que Roderick consigue con creces: para el narrador del cuento de Poe, el primero es «demasiado concreto» en la plasmación de dichas ensoñaciones; el segundo, en cambio, consigue sobrecoger verdaderamente con sus «abstracciones». Alfonso Reyes, por su parte, recurre a un pintor mejicano del siglo XVII para cumplir la misma función: porque no menos indefinible y abstracta es la imagen que Reyes quiere transmitir apoyándose en la pintura de Baltasar Echave de Orio, pues aún está por ver qué cosa sea exactamente esa «expresión de piedad [de las misteriosas anfitrionas del protagonista de La cena «grabada hasta en la dureza de los rasgos» y esas caras iluminadas como «astros enormes y fantásticos». Lo que sí está claro es su sentido: como venimos diciendo, lo significativo de ambos relatos es el desdoblamiento de una de las categorías propias de la ideología de la doble experiencia: ciencia experimental vs. ciencia de lo no asible (Rodríguez, 2OI2: 7I).

4) La huída: tanto al final de La casa Usher como de La cena, asistimos a una saturación de dicha experiencia duplicada o sensibilidad exacerbada y a la consiguiente huida/despertar de sus protagonistas.

\footnotetext{
${ }^{\text {I2 }}$ Para la importancia en la ideología burguesa de las cenas, las sobremesas, los espejos, etc., véase Tras la muerte del aura (En contra y a favor de la Ilustración), op. cit., pp. 80,86 y 87.
} 


\section{Conclusión}

Hemos visto cómo, partiendo de las ideas de sus predecesores en la formación de la literatura/conciencia hispanoamericana, así como de su formación intelectual (tan emparentada con España), Alfonso Reyes desarrolla un discurso de síntesis y universalización de lo hispanoamericano/mejicano a través de su particular desarrollo del llamado «arielismo».

Con todo, la afirmación cultural e ideológica que esto conlleva no es óbice para que, en el caso de nuestro autor, las corrientes literarias europeas con las que voluntariamente se hermana dicho movimiento se dejen informar, también, por las formas y la ideología de otra tradición literaria, la angloamericana, perteneciente al fenómeno que históricamente lo amenaza política y culturalmente: el imperialismo estadounidense. Esto no quiere decir más que lo que ya hemos afirmado: que la producción ideológicoliteraria demuestra lo que el discurso político, moral, religioso, científico, etc., dice y no dice. Es decir: una cosa son las ideologías culturales explícitas y otra es el inconsciente ideológico/literario implícito (Rodríguez, 2002). 


\section{Bibliografía}

- Alvar, M. (I989). Alfonso Reyes y España, Nueva revista de filología hispánica, 37 (2), 299-304.

- Arturo Dávila, S. (2009). El neobarroco sin lágrimas: Góngora, Mallarmé, Alfonso Reyes et al., Hipertexto, 9, 3-35

- Ferrari, O. y Borges, J. L. (1992). Diálogos. Buenos Aires: Seix Barral.

- Hemingway, E. (2004). Up in Michigan, en The First Forty-Nine Stories. London: Arrow Books.

- Madrigal Rodríguez, M. E. (2007). Espejismos y una sombra: La cena de Alfonso Reyes. Literatura Mexicana, I8 (2), I79-193.

- Poe, E. A. (1998). Selected Tales. New York: Oxford University Press.

- Reyes, A. (г993). Obras completas. México: Fondo de Cultura Económica.

- - (т99г). Discurso por la lengua. En E. Ortega (ed.). Redacción y composición, vol. II (pp. 26I-262). La Habana: Pueblo y Educación.

- - (1992). Antología del pensamiento político, social y económico de América latina (Alfonso Reyes). Madrid: Ediciones de Cultura Hispánica.

- - (1998). Correspondencia: Alfonso Reyes / Octavio Paz. México: Fundación Octavio Paz / Fondo de Cultura Económica.

- Rodríguez, J. C. (I990). Teoría e historia de la producción ideológica. Madrid: Akal

- - (2012). Tras la muerte del aura. En contra y a favor de la Ilustración. Granada: Universidad de Granada.

- - (2002). De quéhablamos cuando hablamos de literatura. Granada: Comares.

- - y Salvador, Álvaro (2005). Introducción al estudio de la literatura hispanoamericana, $3^{\mathrm{a}}$ edición. Madrid: Akal.

- - (20I0), Un ejercicio de lectura (De cómo Azorín se inventa a la mujer al leer el Quijote), Alabe, 1, [www.revistaalabe.com]

- Willis Rob, J. (I98I): "La cena” de Alfonso Reyes, cuento onírico: ¿surrealismo o realismo mágico?, en Thesaurus: Boletín del instituto Caro y Cuervo, Tomo 36, $N^{\circ} 2$, pp. 272-283. 